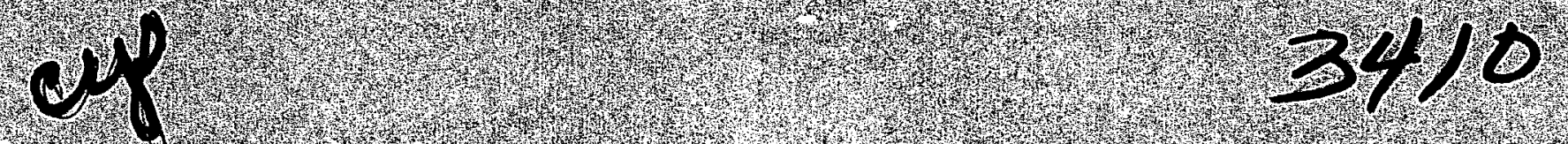

$S C \cdot R=68=1888 \mathrm{~A}$

Technical Report

August 30,1968

PRECISE ABMITAANCE OF A MONOPOLE

Bavid C. Chang

Department of Electri cal Engineer ing

iniver sity of Colorado

Boulder Colorado 80302

Char les W. har rison, Jr.

Sandia Laboratories:

Albuquerque, New Mexico 8715

\title{
SANDIA LABORAIORIES
}

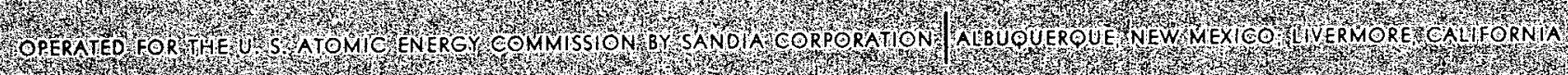




\section{DISCLAIMER}

Portions of this document may be illegible in electronic image products. Images are produced from the best available original document. 
PRECISE ADMITTANCE OF A MONOPOLE

\author{
David C. Chang \\ Department of Electrical Engineering \\ University of Colorado \\ Boulder, Colorado 80302
}

Charles W. Harrison, Jr.

Sandia Laboratories

Albuquerque, New Mexico 87115

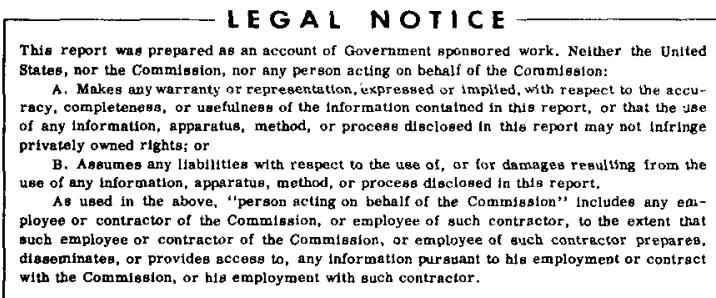

This work was partially supported by the United States Atomic Energy Commission.

DISTRIBUTION OF THIS DOCUMENT IS UNL.IMITED 
ABSTRACT

The purpose of this paper is to obtain the admittance of a monopole antenna to a higher degree of accuracy than has heretofore been reported in the literature. The model selected for analysis consists of a basedriven monopole of arbitrary dimensions (length and radius) protruding perpendicularly from an infinite ground plane. The transmission line providing the excitation is a coaxial cable with outer sheath truncated at ground level.

The problem is solved by obtaining the admittance of the monopole of finite length for TEM excitation alone from an integral equation for the current that has a solution. The requisite information needed to modify this admittance to incorporate the localized cable-monopole junction or feedpoint effect is obtained from the solution of two ancillary problems. One of these problems consists of deriving an expression for the apparent admittance of an infinite monopole considering the TEM and higher order modes of type $\mathrm{TM}_{\text {on }}(\mathrm{n}=1,2, \ldots)$ set up in the coaxial cable by the sheath discontinuity. In essence, this involves solving an integral equation for a function equal to the integral of the electric field across the feedpoint gap. The other supplementary problem requires finding the admittance of an infinite monopole for TEM excitation alone. This is achieved by suitably modifying the integral equation for determining the admittance (for TEM excitation) of the finite structure. 
Extensive numerical results in tabular and graphical form are provided in the paper. $T M_{\text {on }}$ modes in the coaxial cable to $n=400$ are included in the admittance data. 


\section{Introduction}

The tubular monopole considered in this paper consists of a protrusion of the inner conductor of a coaxial cable. The sheath is terminated in an infinite flange which serves as the ground plane. There is no discontinuity in radii of the inner conductor of the coaxial cable and the monopole at any elevation. The composite model is assumed to be perfectly conducting. The truncation of the cable sheath sets up evanescent modes of the $\mathrm{TM}_{\text {on }}$ type $(\mathrm{n}=1,2, \ldots)$ in the line which couple to the monopole at its base. In the admittance data reported in the form of curves, the $\mathrm{TM}_{\mathrm{Oo}}=\mathrm{TEM}$ model plus 400 higher order modes are included.

To solve the problem the following steps are taken:

1. The apparent admittance $\mathrm{Y}_{\mathrm{a} \infty}$ of an infinitely long monopole is determined. This involves principally solving by numerical methods an integral equation for a smooth varying function equal to the integral of the electric field from inner conductor of the coaxial cable to the sheath at ground-plane level.

2. The approximate admittance $\mathrm{Y}_{\text {TEM }}$ of the monopole of finite length is obtained by solving numerically an integral equation for the distribution of current along the radiator, assuming that the monopole is driven only by 
the TEM mode in the coaxial line. The current has no logarithmic singularity at the point of excitation, hence the input admittance is finite and can be obtained to the desired precision.

3. The admittance $\mathrm{Y}_{\text {TEM } \infty}$ of an infinite monopole for TEM mode excitation is obtained by appropriate manipulation of the integral equation used for determining $Y_{\text {TEM }}$ for the finite structure. The final expression is not an integral equation, but some of the integrals that occur are conveniently evaluated using a computer.

4. Having determined $\mathrm{Y}_{\text {a } \infty^{\prime}} \mathrm{Y}_{\mathrm{TEM}}$, and $\mathrm{Y}_{\mathrm{TEM} \infty}$ as described briefly above, the admittance of the monopole of finite length may be written $\mathrm{Y}=\mathrm{Y}_{\mathrm{TEM}}+\mathrm{Y}_{\mathrm{a} \infty}$ $-\mathrm{Y}_{\mathrm{TEM} \infty^{\circ}}$

The writers are of the opinion that the analysis presented here is on a solid footing, even though infinite antenna theory is employed to evaluate monopole-cable junction effects because these effects are confined to a small region near the point of excitation (see Appendix A). But implicit in the derivation is the fact that the length of the antenna must be considerably greater than the inner radius of the sheath of the coaxial cable. In certain ranges of the parameters (such as monopole and cable sheath radii) correlation with other theoretical work based on purely analytical 
procedures as opposed to a synthesis of analytical methods and numerical techniques is possible. In these instances it is found that the cable-

monopole junction effect--expressed as a lumped capacitance--agree perfectly.

Integral Equation for the Radial Electric Field at the Feedpoint of a Tubular

Monopole of Infinite Length

Consider a monopole consisting of an infinite extension of the inner conductor of a coaxial cable of radius $a$, and outer sheath radius $b$, as illustrated by Figure 1. The sheath of the transmission line terminates in an infinite plane. The antenna is normal to the ground plane. The radiator, coaxial line, and ground plane are assumed to be perfectly conducting. Let the incident current on the inner conductor of the coaxial line be

$$
I^{\text {inc }}(z)=e^{i k o^{z}}
$$

The assumed but suppressed time dependence is of the form $\mathrm{e}^{-\mathrm{i} \omega \mathrm{t}}$. It can be demonstrated that the integral equation for the radial component of the electric field $\mathrm{E}_{\mathrm{r}}(\mathrm{r}, 0)$ is

[2]

$$
\int_{a}^{b} r^{\prime} d r^{\prime} E_{r}\left(r^{\prime}, 0\right)\left[G_{o}\left(r, r^{\prime} ; 0\right)+G_{c}\left(r, r^{\prime} ; 0\right)\right]=\frac{i \zeta_{o}}{2 \pi k_{o} r},
$$


where $\zeta_{0}$ is the free-space characteristic impedance and $k_{0}$ is the freespace wave number. $G_{0}\left(r, r^{\prime} ; z\right)$ and $G_{c}\left(r, r^{\prime} ; z\right)$ are the Green's functions in free space and in the coaxial line, respectively. Expressions for these Green's functions can be written down only in terms of their Fourier transforms (Wu 1962). As $\mathrm{z} \rightarrow-\infty$,

$$
\left.G_{c}\left(r, r^{\prime} ; z\right)\right|_{z \rightarrow-\infty} \cong \frac{i}{2 k_{o} \ln \frac{b}{a}}\left(\frac{e^{-i k_{0} z}}{r r^{\prime}}\right) .
$$

With [2] and [3], the apparent terminal input admittance $\mathrm{Y}_{\mathrm{a} \infty}$ of the infinite monopole can be expressed in terms of the integration of $E_{r}\left(r^{\prime}, 0\right)$ across the gap at the driving point $z=0$. It is

$$
Y_{a \infty}=\frac{i 2 \pi}{\zeta_{0} \ln \frac{b}{a}}+2\left[\int_{a}^{b} d r^{\prime} E_{r}\left(r^{\prime}, 0\right)\right]^{-1} .
$$

A more detailed derivation appears in the above mentioned Reference.

In order to solve for $\mathrm{E}_{\mathrm{r}}(\mathrm{r}, 0)$ in [2] numerically, the unknown radial electric field appearing in the integrand must be a smooth varying function. Thus, any singularity involved in the expression for $\mathrm{E}_{r}(r, 0)$ must be first subtracted out from the integrand before any approximations are attempted (Chang, 1967). In the present case, the singularity in $\mathrm{E}_{r}(r, 0)$ actually comes from the edge condition at $r=b$. However, no detailed knowledge of the singularity can be obtained without carrying out an involved 
investigation. Evidently, in order to obtain $Y_{\text {a }}$ from [4], only the integration of $\mathrm{E}_{r}(r, 0)$ across the gap at $z=0$ is needed. Define

$$
f(r)=\int_{a}^{r} E_{r}(r, 0) d r
$$

so that $\mathrm{Y}_{\mathrm{a}_{\infty}}$ is expressed in terms of $\mathrm{f}(\mathrm{r})$ explicitly. Moreover, because the singularity of $\mathrm{E}_{r}(r, 0)$ near any edge behaves at most like $(r-b)^{-1 / 3}$, $f(r)$ is indeed a smooth function over the entire range $a \leq r \leq b$. If use is made of the definition for $f(r)$, [2] may be integrated by parts to yield

$$
\begin{aligned}
& \operatorname{bf(b)}\left[G_{o}(r, b ; 0)+G_{c}(r, b ; 0)\right] \\
& \quad-\int_{a}^{b} d r^{\prime} f\left(r^{\prime}\right) \frac{d}{d r^{\prime}} r^{\prime}\left[G_{o}\left(r, r^{\prime} ; 0\right)+G_{c}\left(r, r^{\prime} ; 0\right)\right] \\
& {[6] \quad \frac{i \zeta_{o}}{2 \pi k_{o} r} .}
\end{aligned}
$$

Introducing the definitions

$$
K\left(r, r^{\prime}\right)=K^{(o)}\left(r, r^{\prime}\right)+K^{(c)}\left(r, r^{\prime}\right) \text {, }
$$

and

[8]

$$
\frac{d}{d r} K^{(p)}\left(r, r^{\prime}\right)=\frac{i}{r^{\prime}} \frac{d}{d r^{\prime}} r^{\prime} G_{p}\left(r, r^{\prime} ; 0\right),
$$


(where p stands for either the superscript o or c), the substitution of [7] into [6] and integration with respect to $r$ results in the new integral equation

[9]

$$
\int_{A}^{B} f\left(R^{\prime}\right) K\left(R, R^{\prime}\right) R^{\prime} d R^{\prime}=\frac{\zeta_{o}}{2 \pi} \ln \frac{R}{A}-f(B) M(R),
$$

where $R=k_{0} r, R^{\prime}=k_{0} r^{\prime}, A=k_{0} a$, and $B=k_{0} b$. Expressions for $K\left(R, R^{\prime}\right)$ and $M(R)$ can be obtained in terms of their Fourier transforms as

$$
\mathrm{K}^{(\mathrm{o})}\left(\mathrm{R}, \mathrm{R}^{\prime}\right)=\frac{1}{4} \int_{\mathrm{C}} \mathrm{d} \lambda\left[\mathrm{H}_{\mathrm{o}}^{(1)}(\xi \mathrm{A})\right]^{-1} \mathrm{H}_{\mathrm{o}}^{(1)}\left(\xi \mathrm{R}_{>}\right)
$$

$$
\begin{aligned}
& {\left[\mathrm{H}_{\mathrm{o}}^{(1)}(\xi \mathrm{A}) \mathrm{J}_{\mathrm{o}}\left(\xi \mathrm{R}_{<}\right)-J_{\mathrm{o}}\left(\xi \mathrm{A}_{\mathrm{O}} \mathrm{H}_{\mathrm{o}}^{(1)}\left(\xi \mathrm{R}_{<}\right)\right],\right.} \\
\mathrm{K}^{(\mathrm{c})}\left(\mathrm{R}, \mathrm{R}^{\prime}\right)= & \frac{1}{4} \int_{\mathrm{C}} \mathrm{d} \lambda[\mathrm{D}(\lambda)]^{-1} \\
& {\left[\mathrm{H}_{\mathrm{o}}^{(1)}(\xi \mathrm{B}) \mathrm{J}_{\mathrm{o}}\left(\xi \mathrm{R}_{>}\right)-\mathrm{J}_{\mathrm{o}}\left(\xi \mathrm{B}_{\mathrm{O}} \mathrm{H}_{\mathrm{o}}^{(1)}\left(\xi \mathrm{R}_{>}\right)\right]\right.} \\
& {\left[\mathrm{H}_{\mathrm{o}}^{(1)}(\xi \mathrm{A}) \mathrm{J}_{\mathrm{o}}\left(\xi_{\mathrm{R}_{<}}\right)-\mathrm{J}_{\mathrm{o}}(\xi \mathrm{A}) \mathrm{H}_{\mathrm{o}}^{(1)}\left(\xi \mathrm{R}_{<}\right)\right], }
\end{aligned}
$$




$$
\mathrm{M}^{(\mathrm{o})}(\mathrm{R})=\frac{\mathrm{B}}{4} \int_{\mathrm{C}} \mathrm{d} \lambda\left[\xi_{\mathrm{O}}^{(1)}(\xi \mathrm{A})\right]^{-1} \mathrm{H}_{\mathrm{o}}^{(1)}\left(\xi_{\mathrm{B}}\right)
$$

$$
\begin{aligned}
& {\left[J_{0}(\xi A) H_{0}^{(1)}(\xi R)-H_{o}^{(1)}(\xi A) J_{0}(\xi R)\right], } \\
M^{(c)}(R)= & \frac{i}{2 \pi} \int_{C} \mathrm{~d} \lambda\left[\xi^{2} \mathrm{D}(\xi)\right]^{-1} \\
& {\left[J_{0}(\xi A) H_{0}^{(1)}(\xi R)-H_{0}^{(1)}(\xi A) J_{0}(\xi R)\right], }
\end{aligned}
$$

and

$$
\mathrm{D}(\lambda)=J_{\mathrm{O}}(\xi \mathrm{A}) \mathrm{H}_{\mathrm{O}}^{(1)}(\xi \mathrm{B})-\mathrm{H}_{\mathrm{O}}^{(1)}(\xi \mathrm{A}) J_{\mathrm{O}}(\xi \mathrm{B}) ;
$$

$$
M(R)=M^{(o)}(R)+M^{(c)}(R),
$$

where $R_{\gtrless}=\max _{\min }\left(R, R^{\prime}\right)$ and $\xi=\sqrt{1-\lambda^{2}}$. The contour $c$ and the chosen branch cuts at $\lambda= \pm 1$ are indicated in Figure 2. Notice that both $K^{(o)}\left(R, R^{\prime}\right)$ and $K^{(c)}\left(r, R^{\prime}\right)$ have logarithmic singularities at $R=R^{\prime}$. These are integrable singularities. Also, the integrands in [11] and [13] have no branch cuts at $\lambda= \pm 1$. In other words, they are single-valued everywhere in the $\lambda$-plane. With $K\left(R, R^{\prime}\right)$ and $M(R)$ defined as above, [9] is then the integral equation to be solved. 


\section{Numerical Solution}

To solve the integral equation [9] numerically, let the integral on the left-hand side be divided into $\mathrm{N}$ intervals, so that each interval has a

length of $2 \Delta$ where $\Delta=\frac{B-A}{2 N}$. As mentioned earlier, $f(R)$ is indeed a smooth function. Therefore, a simple step-function approximation of $f(R)$ should be satisfactory, although a more sophisticated method like a higherorder approximate product integration (Chang 1967) or a piecewise linear or parabolic zoning technique (Taylor, Aronson 1967; Harrington 1967 ) is possible. With this approximation [9] is reduced to:

$$
\begin{aligned}
& \sum_{n=1}^{N} f(A+2 n \Delta-\Delta) \int_{A+2(n-1) \Delta}^{A+2 n \Delta} K\left(R, R^{\prime}\right) R^{\prime} d R^{\prime} \\
& =\frac{\zeta_{O}}{2 \pi} \ln \frac{R}{A}-f(B) M(R) .
\end{aligned}
$$

If [15] is then matched on both sides at the sample points $R_{n}=A+(2 n-1) \Delta$ $\mathrm{n}=1,2, \ldots \mathrm{N}$ and $\mathrm{R}_{\mathrm{N}+1}=\mathrm{B},(\mathrm{N}+1) \times(\mathrm{N}+1)$ matrix equations are obtained. These are

$$
\sum_{n=1}^{N+1} \alpha_{m, n} f_{n}=\frac{\zeta_{o}}{2 \pi} g_{m},
$$

where 


$$
\begin{aligned}
f_{n} & =f\left(R_{n}\right) \\
g_{m} & =\ln \frac{R_{m}}{A} \\
\alpha_{m, n} & =\alpha_{m, n}^{(0)}+\alpha_{m, n}^{(c)}
\end{aligned}
$$

and

[17]

$$
\alpha_{m, n}^{(p)}=\left\{\begin{array}{l}
\int_{X_{2 n-2}}^{X_{2 n}} K^{(p)}\left(R_{m^{\prime}}, R^{\prime}\right) R^{\prime} d^{\prime} ; \quad n \leq N \\
M^{(p)}(R) ; \quad n=N+1
\end{array} .\right.
$$

$X_{n}=n \Delta ; n=1,2, \ldots, 2 N$ and $p$ stand for the superscript (o) or (c). Now, since $K\left(R_{m}, R^{\prime}\right)$ has only an integrable singularity, $\alpha_{m, n}$ is finite for all $\mathrm{m}$ and $n$. Thus, an inversion of [16] will then yield the solution of $f(R)$ at these sample points. The apparent admittance $\mathrm{Y}_{\mathrm{a} \infty}$ can then be obtained by direct substitution of $f(B)$ into [4].

To simplify the evaluation of the matrix element $\alpha_{m, n}$, first define the moment functions $\beta_{\mathrm{K}, \mathrm{L}}^{(\mathrm{p})}$ and $\mu_{\mathrm{K}, \mathrm{L}}^{(\mathrm{p})}$ as 


$$
\beta_{\mathrm{L}, \mathrm{K}}^{(\mathrm{o})}=\frac{\mathrm{X}_{\mathrm{K}}}{4} \int_{\mathrm{C}} \mathrm{d} \lambda\left[\xi_{\mathrm{H}}^{(1)}(\xi \mathrm{A})\right]^{-1} \mathrm{H}_{1}^{(1)}\left(\xi \mathrm{X}_{\mathrm{K}}\right)
$$

[18]

$$
\left[J_{0}\left(\xi X_{L}\right) H_{o}^{(1)}(\xi A)-H_{o}^{(1)}\left(\xi X_{L}\right) J_{o}(\xi A)\right]
$$

$$
\beta_{\mathrm{L}, \mathrm{K}}^{(\mathrm{c})}=\frac{\mathrm{X}_{\mathrm{K}}}{4} \int_{\mathrm{c}} \mathrm{d} \lambda\left[\xi_{\mathrm{D}} \mathrm{D}(\lambda)\right]^{-1}\left[\mathrm{H}_{\mathrm{o}}^{(1)}(\xi \mathrm{B}) \mathrm{J}_{1}\left(\xi \mathrm{X}_{\mathrm{K}}\right)-\mathrm{J}_{\mathrm{o}}\left(\xi_{\mathrm{B}}\right) \mathrm{H}_{1}^{(1)}\left(\xi \mathrm{X}_{\mathrm{K}}\right)\right]
$$

[19]

$$
\left[\mathrm{H}_{0}^{(1)}(\xi \mathrm{A}) J_{0}\left(\xi \mathrm{X}_{\mathrm{L}}\right)-J_{\mathrm{o}}(\xi \mathrm{A}) \mathrm{H}_{\mathrm{O}}^{(1)}\left(\xi \mathrm{X}_{\mathrm{L}}\right)\right]
$$

$$
\mu_{\mathrm{L}, \mathrm{K}}^{(o)}=\frac{\mathrm{X}_{\mathrm{K}}}{4} \int_{\mathrm{c}} \mathrm{d} \lambda\left[\xi_{\mathrm{o}}^{(1)}(\xi \mathrm{A})\right]^{-1} \mathrm{H}_{\mathrm{o}}^{(1)}\left(\xi \mathrm{X}_{\mathrm{L}}\right)
$$

[20]

$$
\begin{gathered}
{\left[\mathrm{H}_{\mathrm{O}}^{(1)}(\xi \mathrm{A}) \mathrm{J}_{1}\left(\xi \mathrm{X}_{\mathrm{K}}\right)-\mathrm{J}_{\mathrm{o}}(\xi \mathrm{A}) \mathrm{H}_{1}^{(1)}\left(\xi \mathrm{X}_{\mathrm{K}}\right)\right]} \\
\mu_{\mathrm{L}, \mathrm{K}}^{(\mathrm{c})}=\frac{\mathrm{X}_{\mathrm{K}}}{4} \int_{\mathrm{c}} \mathrm{d} \lambda[\xi \mathrm{D}(\lambda)]^{-1}\left[\mathrm{H}_{\mathrm{O}}^{(1)}(\xi \mathrm{B}) \mathrm{J}_{\mathrm{o}}\left(\xi \mathrm{X}_{\mathrm{L}}\right)-\mathrm{J}_{\mathrm{o}}(\xi \mathrm{B}) \mathrm{H}_{\mathrm{O}}^{(1)}\left(\xi \mathrm{X}_{\mathrm{L}}\right)\right]
\end{gathered}
$$

[21]

$$
\left[\mathrm{H}_{\mathrm{O}}^{(1)}(\xi \mathrm{A}) \mathrm{J}_{1}\left(\xi \mathrm{X}_{\mathrm{K}}\right)-\mathrm{J}_{\mathrm{o}}(\xi \mathrm{A}) \mathrm{H}_{1}^{(1)}\left(\xi \mathrm{X}_{\mathrm{K}}\right)\right]
$$

Then, with some manipulations, it is not difficult to show that for $m \leq N$ 


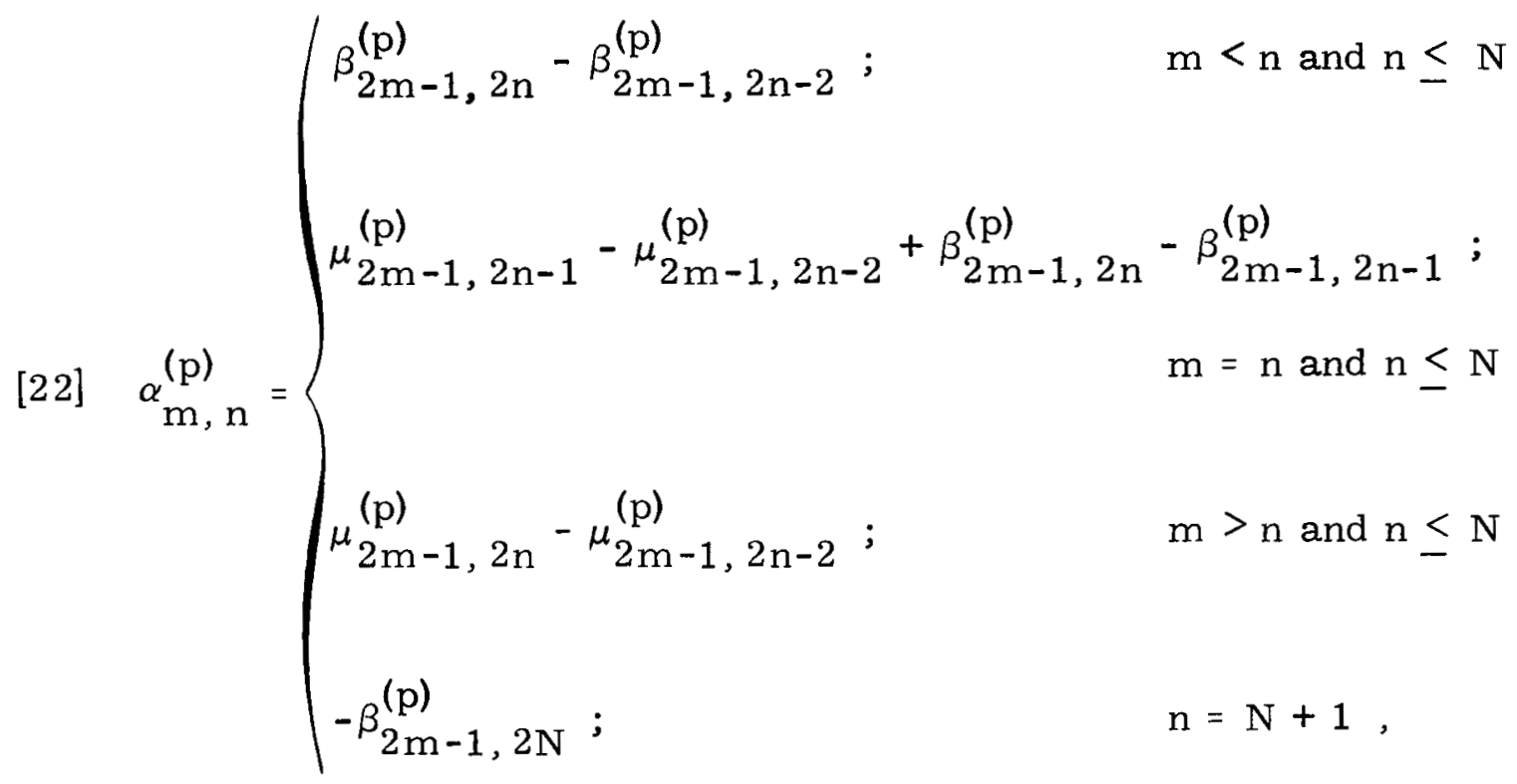

also, for $m=N+1$, all $2 m-1$ in the subscripts should be replaced by $2 \mathrm{~N}$.

Evaluation of the Moment Functions

A. To evaluate the moment functions $\beta_{L, K}^{(o)}, \mu_{L, K}^{(o)}$ numerically, first observe that, as $\lambda \rightarrow \infty$, the integrands of

$$
\left.\begin{array}{c}
\beta_{L, K}^{(0)} \\
\mu_{L, K}^{(0)}
\end{array}\right\} \cong \frac{-i X_{K}}{4 \pi \lambda^{2}} e^{-\lambda|L-K| \Delta},
$$

i. e., both integrands decay exponentially when $L \neq K$, and at least as fast as $1 / \lambda^{2}$, when $L=K$. Indeed, the integration path $c$ on the real axis is the fastest converging path in the $\lambda$-plane. Therefore, no deformation 
of the contour is needed. Near the branch points $\left(\lambda= \pm 1+\delta \mathrm{e}^{i \theta}\right)$, the behaviors of the two integrands are quite different. As $\delta \rightarrow 0$, the integrands of $\beta_{L, K}^{(0)}$ and $\mu_{L, K}^{(0)}$ may be written

$$
\text { integrand of } \beta_{L, K}^{(o)} \cong \frac{i}{4 \pi}\left[\left(\ln \frac{X_{L}}{A}\right) \delta e^{i \theta} \ln \delta\right]^{-1} \text {, }
$$

$$
\text { integrand of } \mu_{\mathrm{L}, \mathrm{K}}^{(\mathrm{o})} \cong \frac{\mathrm{i}}{4 \pi}\left(\delta \mathrm{e}^{\mathrm{i} \theta}\right)^{-1}
$$

Therefore, the contribution from the contour integration around the branch points is zero for $\beta_{L, K}^{(0)}$, but equals to $-1 / 2$ for $\mu_{L, K^{*}}^{(o)}$ Nevertheless, since both [24] and [25] are independent of $X_{K}$, the contribution around the branch points, if any, is irrelevant to the evaluation of $\alpha(\mathrm{o})$ for $n<N+1$. Moreover, in order to improve the accuracy and to speed up the computation, it is helpful to subtract out any leading terms which have the behaviors of [24] and [25] near the branch point, and still not change the value of $\alpha_{m, n}^{(o)}$ for $n<N+1$. Therefore, one rewrites [18] as 


$$
\begin{aligned}
& \beta_{L, K}^{(o)}=\frac{X_{K}}{2}\left\{\int_{0}^{\lambda} 1\right. \\
& {\left[J_{o}\left(\xi X_{L}\right) H_{o}^{(1)}(\xi A)-J_{o}\left(\xi A_{0} H_{o}^{(1)}\left(\xi X_{L}\right)\right]\right.} \\
& +\int_{0}^{\sqrt{1-\lambda_{1}^{2}}} \mathrm{~d} \lambda\left[\xi_{\mathrm{H}}^{(1)}(\lambda \mathrm{A})\right]^{-1} \mathrm{H}_{1}^{(1)}\left(\lambda \mathrm{X}_{\mathrm{K}}\right) \\
& {\left[J_{0}\left(\lambda X_{L}\right) H_{o}^{(1)}(\lambda A)-J_{0}(\lambda A) H_{o}^{(1)}\left(\lambda X_{L}\right)\right]} \\
& +\frac{i 2}{\pi} \int_{0}^{\infty} \mathrm{d} \lambda\left[\sqrt{1+\lambda^{2}} \mathrm{~K}_{\mathrm{o}}(\lambda \mathrm{A})\right]^{-1} \mathrm{~K}_{1}\left(\lambda \mathrm{X}_{\mathrm{K}}\right) \\
& \left.\left[\mathrm{I}_{0}\left(\lambda \mathrm{X}_{\mathrm{L}}\right) \mathrm{K}_{\mathrm{o}}(\lambda \mathrm{A})-\mathrm{I}_{\mathrm{o}}(\lambda \mathrm{A}) \mathrm{K}_{\mathrm{o}}\left(\lambda \mathrm{X}_{\mathrm{L}}\right)\right]\right\} \text {, }
\end{aligned}
$$

where $\lambda_{1}$ is a convenient number such that $0<\lambda_{1}<1$, but not too close to either 0 or 1 . If a term

$$
\int_{0}^{\lambda_{2}} \frac{d x}{x}\left\{\left[\ln \frac{A x}{2}+v-\frac{i \pi}{2}\right]^{-1}+\left[\ln \frac{A x}{2}+v\right]^{-1}\right\}
$$

where $0<\lambda_{2} \leq \lambda_{1}<1, \lambda_{2} \mathrm{~A} \ll<1$, and $v$ is the Euler's constant $(v=0.5772)$ is added and subtracted from [26], the convergence of the integration near the branch point $\lambda=1$ will be improved 


$$
\begin{aligned}
& \beta_{\mathrm{L}, \mathrm{K}}^{(\mathrm{o})}=\frac{\mathrm{X}_{\mathrm{K}}}{2}\left\{\int_{\mathrm{O}}^{\lambda} \mathrm{d} \lambda\left[\xi_{\mathrm{H}}^{(1)}\left(\xi_{\mathrm{A}}\right)\right]^{-1} \mathrm{H}_{1}^{(1)}\left(\xi \mathrm{X}_{\mathrm{K}}\right)\right. \\
& {\left[J_{0}\left(\xi \mathrm{X}_{\mathrm{L}}\right) \mathrm{H}_{\mathrm{O}}^{(1)}(\xi \mathrm{A})-\mathrm{J}_{\mathrm{o}}(\xi \mathrm{A}) \mathrm{H}_{\mathrm{O}}^{(1)}\left(\xi \mathrm{X}_{\mathrm{L}}\right)\right]} \\
& +\int_{\lambda_{2}}^{\sqrt{1-\lambda_{1}^{2}}} \mathrm{~d} \lambda\left[\xi \mathrm{H}_{\mathrm{O}}^{(1)}(\lambda \mathrm{A})\right]^{-1} \mathrm{H}_{1}^{(1)}\left(\lambda \mathrm{X}_{\mathrm{K}}\right) \\
& {\left[J_{0}\left(\lambda X_{L}\right) H_{o}^{(1)}(\lambda A)-J_{0}(\lambda A) H_{o}^{(1)}\left(\lambda X_{L}\right)\right]} \\
& +\frac{i 2}{\pi} \int_{\lambda_{2}}^{\lambda} \mathrm{d} \lambda\left[\sqrt{1+\lambda^{2}} \mathrm{~K}_{\mathrm{o}}(\lambda \mathrm{A})\right]^{-1} \mathrm{~K}_{1}\left(\lambda \mathrm{X}_{\mathrm{K}}\right) \\
& \left.\left[K_{o}(\lambda A) I_{o}\left(\lambda X_{L}\right)-I_{o}(\lambda A) K_{o}\left(\lambda X_{L}\right)\right]+C_{1}\left(\lambda_{3}, X_{L}, X_{K}\right)\right\} \\
& +\frac{i}{\pi}\left(\ln \frac{\mathrm{X}_{\mathrm{L}}}{\mathrm{A}}\right)^{-1}\left\{\int _ { 0 } ^ { \lambda } \frac { \mathrm { d } \lambda } { \lambda } \left[\left(\frac{1}{\sqrt{1-\lambda^{2}}}-1\right) \frac{1}{\ln \frac{\mathrm{A} \lambda}{2}+v-\frac{\mathrm{i} \pi}{2}}\right.\right. \\
& \left.\left.+\left(1-\frac{1}{\sqrt{1+\lambda^{2}}}\right) \frac{1}{\ln \frac{A \lambda}{2}+v}\right]+\ln \left[1-\frac{i \pi}{2}\left(\ln \frac{\lambda_{2} A}{2}+v\right)^{-1}\right]\right\} \text {. }
\end{aligned}
$$

[27]

17 
In [27], $A \lambda_{3} \gg 1, \mathrm{C}_{1}\left(\lambda_{3}, \mathrm{X}_{\mathrm{L}}, \mathrm{X}_{\mathrm{K}}\right)$ is a correction term that arises by integrating from $\lambda_{3}$ to $\infty$. Its value is given in Appendix B. Equation [27] is then in final form for computation. As mentioned earlier, the second bracket in [27] is independent of $\mathrm{X}_{\mathrm{K}}$, and therefore contributes only to $\alpha^{(0)}$ ${ }^{\alpha} \mathrm{m}, \mathrm{N}+1^{\circ}$

Similarly, the expression for $\mu_{L, K}^{(0)}$ can be obtained as

$$
\begin{aligned}
& \mu_{L, K}^{(o)}=\frac{X_{K}}{2}\left\{\int_{0}^{\lambda} \mathrm{d} \lambda\left[\xi_{\mathrm{O}}^{(1)}(\xi \mathrm{A})\right]^{-1} \mathrm{H}_{\mathrm{o}}^{(1)}\left(\xi_{\mathrm{X}}\right)\right. \\
& {\left[\mathrm{H}_{\mathrm{o}}^{(1)}(\xi \mathrm{A}) \mathrm{J}_{1}\left(\xi \mathrm{X}_{\mathrm{K}}\right)-J_{\mathrm{o}}\left(\xi \mathrm{A}_{1} \mathrm{H}_{1}^{(1)}\left(\xi \mathrm{X}_{\mathrm{K}}\right)\right]\right.} \\
& +\int_{\lambda_{2}}^{\sqrt{1-\lambda_{1}^{2}}} \mathrm{~d} \lambda\left[\xi_{\mathrm{o}}^{(1)}(\lambda \mathrm{A})\right]^{-1} \mathrm{H}_{\mathrm{o}}^{(1)}\left(\lambda \mathrm{X}_{\mathrm{L}}\right) \\
& {\left[\mathrm{H}_{\mathrm{O}}^{(1)}(\lambda \mathrm{A}) J_{1}\left(\lambda \mathrm{X}_{\mathrm{K}}\right)-J_{\mathrm{o}}(\lambda \mathrm{A}) \mathrm{H}_{1}^{(1)}\left(\lambda \mathrm{X}_{\mathrm{K}}\right)\right]} \\
& -\frac{i 2}{\pi} \int_{\lambda_{2}}^{\lambda} \mathrm{d} \lambda\left[\sqrt{1+\lambda^{2}} \mathrm{~K}_{\mathrm{o}}(\lambda \mathrm{A})\right]^{-1} \mathrm{~K}_{\mathrm{o}}\left(\lambda \mathrm{X}_{\mathrm{L}}\right) \\
& {\left[\mathrm{K}_{\mathrm{o}}(\lambda \mathrm{A}) \mathrm{I}_{1}\left(\lambda \mathrm{X}_{\mathrm{K}}\right)+\mathrm{I}_{\mathrm{o}}(\lambda \mathrm{A}) \mathrm{K}_{1}\left(\lambda \mathrm{X}_{\mathrm{K}}\right)\right]} \\
& \left.+C_{2}\left(\lambda_{3}, x_{L}, x_{K}\right)\right\}+\left\{\text { functions independent of } x_{K}\right\} \text {. }
\end{aligned}
$$


The value of $C_{2}\left(\lambda_{3}, X_{L}, X_{K}\right)$ is given in Appendix $B$.

B. Evaluation of the moment functions $\beta_{L, K}^{(c)}$ and $\mu_{L, K}^{(c)}$ can be done directly from [19] and [21]. This is because the contour integration enclosing the lower half-plane contains only simple poles, which correspond to all $\mathrm{TM}_{\text {on }}$-modes of the coaxial line. At $\lambda= \pm 1$, instead of having a pair of branch points, the integrands in [19] and [21] have only two simple poles which correspond exactly to the fundamental TEM-mode of the line. Thus, if the roots of the equation $D(\lambda)=0$ are $\lambda_{p}$ and $\xi_{\mathrm{p}}=\sqrt{1-\lambda_{\mathrm{p}}^{2}}$, then the use of the residue theorem yields direct results for both $\beta_{\mathrm{L}, \mathrm{K}}^{(\mathrm{c})}$ and $\mu_{\mathrm{L}, \mathrm{K}}^{(\mathrm{c})}$ in terms of these poles. Furthermore, the large zeros of $D(\lambda)$ (high-order modes) can readily be obtained from the asymptotic expansion as

$$
\xi_{p}=\frac{P \pi}{B-A} \text { or } \quad \lambda_{p}=-i\left[\left(\frac{P \pi}{B-A}\right)^{2}-1\right]^{1 / 2}
$$

Accordingly, 


$$
\begin{aligned}
\beta_{L,-K}^{(c)}= & -\frac{1}{2}\left[\ln \frac{B}{A}\right]^{-1} \ln \frac{X_{L}}{A}+\frac{\pi}{2} X_{K} \sum_{p=1}^{N}\left[\xi \frac{d}{d \lambda} D(\lambda)\right]_{\lambda=\lambda}^{-1} \\
& {\left[Y_{o}\left(\xi_{p} B\right) J_{1}\left(\xi_{p} X_{K}\right)-J_{o}\left(\xi_{p} B\right) Y_{1}\left(\xi p X_{K}\right)\right] } \\
& {\left[Y_{o}(\xi p A) J_{o}\left(\xi_{p} X_{L}\right)-J_{o}\left(\xi_{p} A\right) Y_{o}\left(\xi_{p} X_{L}\right)\right] } \\
& +\frac{i}{2 \pi^{2}}(B-A)\left(\frac{X_{K}}{X_{L}}\right)^{1 / 2} \sum_{p=N}^{\infty} \frac{1}{p^{2}} \cos \frac{X_{K}-A}{B-A} \sin \frac{X_{L}-A}{B-A},
\end{aligned}
$$

and

$$
\begin{aligned}
\mu_{L, K}^{(c)}=- & \left.\frac{1}{2}\left[\ln \frac{B}{A}\right]^{-1} \ln \frac{X_{L}}{A}+\frac{\pi}{2} X_{K} \sum_{p=1}^{N}\left[\xi \frac{d}{d \lambda} D(\lambda)\right]_{\lambda=\lambda}\right]_{p} \\
& {\left[Y_{o}\left(\xi_{p} B\right) J_{o}\left(\xi X_{L}\right)-J_{o}\left(\xi_{p} B\right) Y_{o}\left(\xi_{p} X_{L}\right)\right] } \\
& {\left[Y_{o}\left(\xi_{p} A\right) J_{1}\left(\xi_{p} X_{K}\right)-J_{o}(\xi p) Y_{1}\left(\xi_{p} X_{K}\right)\right] } \\
+ & \frac{i}{2 \pi^{2}}(B-A)\left(\frac{X_{K}}{X_{L}}\right)^{1 / 2} \sum_{p=N}^{\infty} \frac{1}{p^{2}} \cos \frac{X_{K}-A}{B-A} \sin \frac{X_{L}-A}{B-A},
\end{aligned}
$$

$$
\xi_{\mathrm{N}} \mathrm{A} \gg 1 \text {. Equations [30] and [31] }
$$
are then the computation forms. Again, the first term in [30] contributes only to $\alpha_{\mathrm{m}, \mathrm{N}+1^{\circ}}^{(\mathrm{c})}$ 
Integral Equation for the Distribution of Current

Along a Tubular Monopole of Finite Length

for TEM-Mode Excitation

In a recently published paper (Chang 1968) an integral equation for the current distribution along a perfectly conducting tubular monopole driven at its base by a coaxial transmission line is derived, which includes a term for the feedpoint correction so that no singularity exists in the current. The equation is

$$
\begin{aligned}
& \int_{0}^{h} I_{t}\left(z^{\prime}\right)\left[K_{a}\left(z-z^{\prime}\right)+K_{a}\left(z+z^{\prime}\right)\right] d z^{\prime} \\
& =\frac{i 4 \pi}{\zeta_{0}}\left\{C \cos k_{o} z+V \sin k_{o} z+V\left[\ln \frac{b}{a}\right]^{-1}\right. \\
& \left.\left[f(z)-f(0) \cos k_{0} z\right]\right\} ; \quad z \leq h
\end{aligned}
$$

where $k_{a}(z)$ and $f(z)$ are defined by [9] and [18] of the above-mentioned reference. Equation [32] has been solved by inversion of a matrix obtained by assuming that the current is a continuous piecewise linear function. Evidently, for unit driving voltage $V$, the input admittance $Y_{\text {TEM }}$ is simply $I_{t}(0)$. This important quantity has been tabulated for a range of the parameters $h / \lambda, a / \lambda$, and $b / a . *$

\footnotetext{
*E. A. Aronson and C. W. Harrison, Jr., "The Distribution of Current Along a Base-Driven Tubular Monopole of Arbitrary Dimensions Oriented Perpendicular to a Highly Conducting Ground Screen, "Sandia Laboratories Technical Report SC-R-68-1706, April 1968 (unpublished).
} 
The Admittance of an Infinite Monopole for TEM-Mode Excitation

As $h \rightarrow \infty$, the Fourier transform of $I_{t}(z)$ can be solved readily by the convolution theorem. Thus,

$$
\mathrm{Y}_{\mathrm{TEM} \infty}=\frac{1}{\zeta_{\mathrm{o}}}\left[\ln \frac{\mathrm{B}}{\mathrm{A}}\right]^{-1} \int_{\mathrm{C}} \mathrm{d} \lambda \xi^{-2}\left\{1-\left[\mathrm{H}_{\mathrm{O}}^{(1)}(\mathrm{A} \xi)\right]^{-1} \mathrm{H}_{\mathrm{o}}^{(1)}(\mathrm{B} \xi)\right\}
$$

A derivation similar to that leading to [27] will then yield

$$
\begin{aligned}
& \mathrm{Y}_{\mathrm{TEM} \infty}=\frac{\mathrm{i} 4}{\zeta_{\mathrm{o}}}\left[\ln \frac{\mathrm{B}}{\mathrm{A}}\right]^{-1}\left[\int_{0}^{\lambda_{1}} \mathrm{~d} \lambda \xi^{-2}\left\{1-\left[\mathrm{H}_{\mathrm{O}}^{(1)}(\mathrm{A} \xi)\right]^{-1} \mathrm{H}_{\mathrm{O}}^{(1)}(\mathrm{B} \xi)\right\}\right. \\
& +\int_{\lambda_{2}}^{\sqrt{1-\lambda_{1}^{2}}} \mathrm{~d} \lambda(\lambda \xi)^{-1}\left\{1-\left[\mathrm{H}_{\mathrm{o}}^{(1)}(\mathrm{A} \lambda)\right]^{-1} \mathrm{H}_{\mathrm{o}}^{(1)}(\mathrm{B} \lambda)\right\} \\
& \left.+\int_{\lambda_{2}}^{\lambda_{3}} \mathrm{~d} \lambda\left(\lambda \sqrt{1+\lambda^{2}}\right)^{-1}\left\{\left[\mathrm{~K}_{\mathrm{o}}(\lambda \mathrm{A})\right]^{-1} \mathrm{~K}_{\mathrm{o}}(\lambda \mathrm{B})-1\right\}+\mathrm{C}_{3}\left(\lambda_{3}\right)\right] \\
& -\frac{i}{\zeta_{0}}\left\{\int _ { 0 } ^ { \lambda } { } _ { 0 } d \lambda \lambda ^ { - 1 } \left[\left(\frac{1}{\sqrt{1-\lambda^{2}}-1}\right)\left(\ln \frac{A \lambda}{2}+v-\frac{i \pi}{2}\right)^{-1}\right.\right. \\
& \left.\left.+\left(1-\frac{1}{\sqrt{1+\lambda^{2}}}\right)\left(\ln \frac{\mathrm{A} \lambda}{2}+v\right)\right]+\ln \left[1-\frac{\mathrm{i} \pi}{2}\left(v+\ln \frac{\mathrm{A} \lambda}{2}\right)^{-1}\right]\right\} \text {. }
\end{aligned}
$$


An expression for $C_{3}\left(\lambda_{3}\right)$ is given in Appendix B.

Having obtained $Y_{a \infty}$ from [4], $Y_{T E M}$ from [32], and $Y_{T E M \infty}$ from [34], one is in a position to write down an expression for the admittance $\mathrm{Y}$ of a tubular monopole of finite length driven at its base by a coaxial cable. This expression is

$$
\mathrm{Y}=\mathrm{Y}_{\mathrm{TEM}}+\mathrm{Y}_{\mathrm{a} \infty}-\mathrm{Y}_{\mathrm{TEM} \infty}
$$

It is apparent to the reader that the admittances comprising [35] are obtained from a synthesis of analytical methods and numerical techniques (see Appendix A). As a check, it can be shown that whenever $(b-a) / a \ll 1$ and $(b-a) \ll \lambda$ that (Chang, Wu 1968)

$$
\mathrm{Y}_{\mathrm{a} \infty}-\mathrm{Y}_{\mathrm{TEM} \infty}=i \frac{4 \mathrm{k}_{\mathrm{O}} \mathrm{a}}{\zeta_{\mathrm{O}}} \ln \frac{4}{\pi}
$$

$\left(\ln \frac{4}{\pi}=0.24153\right)$. Numerical results based on the present theory have been compared with those obtained from [36] when the above inequalities are satisfied, and perfect agreement obtains (Chang 1968).

\section{Numerical Results}

In Table I the function $f(r)$ given by [9] is tabulated against $(r-a) /$ (b-a), $a \leq r \leq b$, for $b / a=2$ and $a / \lambda=0.159$ where $\lambda$ now represents the free-space wavelength. The data indicate that $f(r)$ varies smoothly with $r$, although $\mathrm{E}_{r}(r, 0)$ is singular at $r=b$. 
In Table II, $\mathrm{Y}_{2 \infty^{\circ}} \mathrm{Y}_{\text {TEM } \infty}$, and $\left(\mathrm{Y}_{2 \infty}-\mathrm{Y}_{\mathrm{TEM} \infty}\right)$ are presented in tabular form for selected values of $a / \lambda$ and $b / a$. From this table it is clear that the real part of $\left(\mathrm{Y}_{\mathrm{a} \infty}-\mathrm{Y}_{\mathrm{TEM} \infty}\right)$ is consistently much smaller than the imaginary part. Thus the feedpoint correction is predominantly susceptive in character. The rule of thumb is that $\mathrm{Y}_{\mathrm{a} \infty} \simeq \mathrm{Y}_{\mathrm{TEM} \infty}$ (i.e., no correction is needed for the coupling between the transmission line and the monopole) provided $a / \lambda<0.01$ and $b / a<10$. The writers are of the opinion that the real part of $\left(\mathrm{Y}_{a \infty}-\mathrm{Y}_{\mathrm{TEM} \mathrm{N}_{\infty}}\right)$ is due to direct radiation from the open end of the coaxial line. The larger $(b-a)$ the greater the conductance correction.

Figures 3-5 give the corrected driving point admittance $Y=G-i B$ against $h / \lambda$ for the same values of $a / \lambda$ and $b / a$ used in Table II. An examination of these figures shows that the input susceptance of a monopole of finite length is influenced by the ratio $\mathrm{b} / \mathrm{a}$.

In Figures 6-8 the normalized magnitude of the modal current distribution along an infinite monopole is given for three values of $\mathrm{k}_{\mathrm{o}} \mathrm{a}$ and selected values of $\mathrm{b} / \mathrm{a}$. For example, from Figure 8 , when $\mathrm{b} / \mathrm{a}=1.25$ and $k_{0} z=0.8,\left|I_{t}(z)\right|=0.002\left|I_{02}\right|$. Here $\left|I_{t}(z)\right|$ is the $\mathrm{TM}_{02}$ current at the specified distance from the driving point. The feedpoint current for this mode has the value $\left|\mathrm{I}_{02}\right|$. Evidently, the higher the mode the more rapid the attenuation of current along the antenna referred to the input value (see Appendix A). Thus, the data presented in these figures justify the use of infinite antenna theory to obtain the feedpoint correction for a finite monopole. 


\section{Conclusions}

In this paper a procedure has been presented for obtaining the admittance of a tubular monopole antenna for the ranges of dimensions currently in use. Heretofore the inequalities $(b-a) / a<<1$ and $(b-a) \ll \lambda$ had to be imposed. In the present theory the restriction $(b-a) / a \ll 1$ is not introduced in the solution of the problem. Furthermore, it is shown in Appendix A and accompanying curves that the restriction $(b-a)<\lambda(i . e .,(b-a) \leq \lambda / 100)$ can be relaxed to $(b-a)$ $<\lambda / 10$ and the feedpoint correction still be based on infinite antenna theory. This condition precludes the monopole from being driven significantly by propagating $T M_{\text {on }}$ modes in the coaxial line. As a practical matter antenna designers probably would not want to construct an antenna system violating the condition $(b-a)<\lambda / 10$.

\section{Acknowledgment}

The writers thank Deyoe Sutton for typing this paper. Roma Schramm and Danny Ooten prepared the figures. Dorothy Mann proofed the paper. 
TABLE I

\begin{tabular}{cc}
$\begin{array}{r}\text { Variation of } f(r) \text { as a function of }(r-a) /(b-a) ; \\
a / \lambda=0.01590, b / a=2.00\end{array}$ \\
$\begin{array}{c}(r-a) /(b-a) \\
0.000\end{array}$ & $0.00+i 0.00$ \\
0.083 & $10.61+i 1.64$ \\
0.250 & $27.52+i 4.25$ \\
0.417 & $39.49+\mathrm{i} 6.10$ \\
0.583 & $48.16+\mathrm{i} 7.44$ \\
0.750 & $54.61+\mathrm{i} 8.46$ \\
0.917 & $59.39+\mathrm{i} 9.23$ \\
1.000 & $62.19+\mathrm{i} 9.70$ \\
\hline
\end{tabular}


TABLE II

Correction to the TEM-mode excitation for an infinitely long antenna

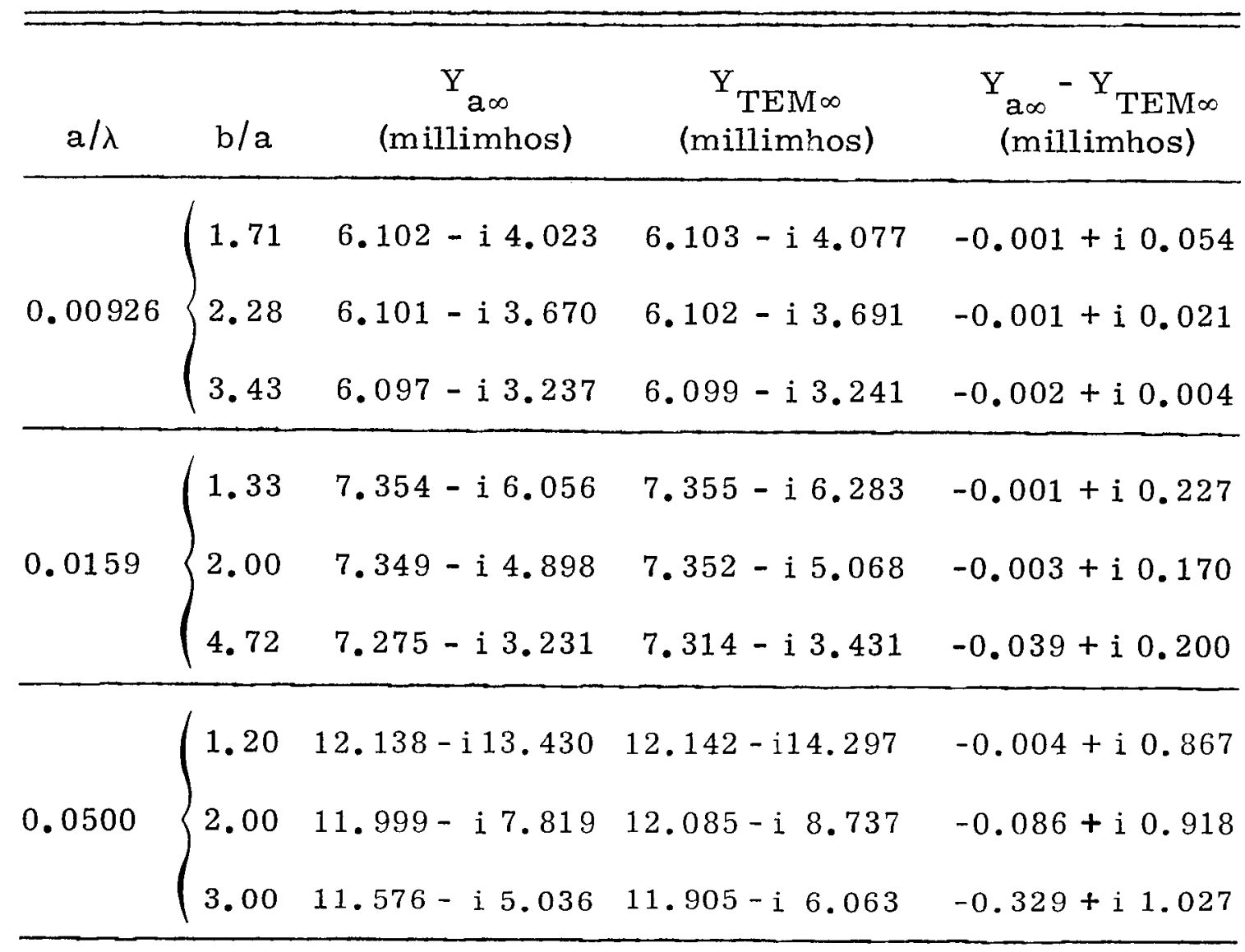




\section{APPENDIX A}

Following a study of this paper many readers will be of the opinion that proof must be exhibited that [35] is valid. This involves demonstrating that the modal currents $\mathrm{TM}_{\text {on }}(\mathrm{n}=1,2, \ldots)$ in the vicinity of the feedpoint of an infinite monopole are evanescent; these currents must attenuate rapidly with increasing $\mathrm{k}_{\mathrm{o}} \mathrm{z}$ especially when $\mathrm{k}_{\mathrm{O}} \mathrm{a}$ is small. If this turns out to be true, then the feedpoint correction for the monopole of finite length may be based on infinite cylindrical antenna theory. The need for a driving point correction arises mainly because of susceptive coupling of the coaxial line to the monopole at their junction.

The distribution of the electric field across the gap of an infinite monopole is assumed to be

$$
[A-1] \quad E_{r}(r, 0)=E_{n o}\left[J_{o}\left(k_{n} a\right) H_{1}^{(1)}\left(k_{n} r\right)-J_{1}\left(k_{n} r\right) H_{o}^{(1)}\left(k_{n} a\right)\right] \text {, }
$$

where $\mathrm{E}_{\text {no }}$ is an arbitrary constant and $\mathrm{k}_{\mathrm{n}}$ is the nth zero of the following modal equation:

$$
\text { [A-2] } \quad J_{0}\left(k_{n} a\right) H_{o}^{(1)}\left(k_{n} b\right)-J_{o}\left(k_{n} b\right) H_{o}^{(1)}\left(k_{n} a\right)=0 \text {. }
$$

Observe that $[A-1]$ gives the $E_{r}$ field in the coaxial cable associated with the $\mathrm{TM}$ on mode. 
The electric field directed tangential to the surface of the antenna is given by

$$
\begin{aligned}
& E_{z}(r, z)=\frac{1}{r} \frac{\partial}{\partial r} r\left[-\left.\frac{1}{a} \int_{0}^{\infty} I_{t n}\left(z^{\prime}\right) \frac{\partial}{\partial r^{\prime}} r^{\prime} G\left(r, r^{\prime} ; z, z^{\prime}\right)\right|_{r^{\prime}=a} d z^{\prime}\right. \\
& \text { [A -3] } \\
& \left.+2 \pi \int_{a}^{b} i \epsilon_{o} \omega E_{r^{\prime}}\left(r^{\prime}, 0\right) G\left(r, r^{\prime} ; z, 0\right) r^{\prime} d r^{\prime}\right] \quad 0 \leq z \leq \infty,
\end{aligned}
$$

where $I_{t n}$ is the current induced on the antenna surface due to the excitation of a TM on $^{-m o d e}$ and G is the Green's function defined elsewhere (Chang 1968). Imposing the boundary condition $\mathrm{E}_{\mathrm{z}}(\mathrm{a}, \mathrm{z})=0$, the integral equation for $I_{t}(z)$ is obtained. Its solution is readily effected in terms of its Fourier transform, i. e.,

$$
I_{t n}(z)=\frac{i 2 k_{o}}{\zeta_{0}} \int_{-\infty}^{\infty}\left[\left(k_{o}^{2}-\lambda^{2}\right) H_{o}^{(1)}(\xi a) J_{o}(\xi a)\right]^{-1} N(\lambda) e^{-i \lambda z} d \lambda
$$

$[A-4]$

$$
0 \leq \mathrm{z} \leq \infty
$$

Here

$[\mathrm{A}-5]$

$$
\mathrm{N}(\lambda)=\mathrm{i} \pi \xi \mathrm{J}_{\mathrm{o}}(\mathrm{a} \xi) \int_{\mathrm{a}}^{\mathrm{b}} \mathrm{r}^{\prime} \mathrm{E}_{\mathrm{r}}\left(\mathrm{r}^{\prime}, 0\right) \mathrm{H}_{1}^{(1)}\left(\mathrm{r}^{\prime} \xi\right) \mathrm{d} \mathrm{r}^{\prime}
$$

In $[A-4]$ and $[A-5], \xi=\sqrt{k_{0}^{2}-\lambda^{2}}$ and the branch cuts associated with $\lambda= \pm \mathrm{k}_{\mathrm{o}}$ are so chosen that $0 \leq \arg \xi \leq \pi$. Substitution of $[\mathrm{A}-1]$ into [A-5] yields 


$$
\begin{aligned}
\mathrm{N}(\lambda)= & -\frac{2 \mathrm{E}}{\mathrm{k}_{\mathrm{n}}} \xi^{2}\left(\xi^{2}-\mathrm{k}_{\mathrm{n}}^{2}\right)^{-1} \mathrm{~J}_{\mathrm{o}}(\mathrm{a} \xi)\left\{\left[\mathrm{J}_{\mathrm{o}}\left(\mathrm{k}_{\mathrm{n}} \mathrm{b}\right)\right]^{-1} \mathrm{~J}_{\mathrm{o}}\left(\mathrm{k}_{\mathrm{n}} \mathrm{a}\right) \mathrm{H}_{\mathrm{o}}^{(1)}(\xi \mathrm{b})\right. \\
& \left.-\mathrm{H}_{\mathrm{o}}^{(1)}(\xi \mathrm{a})\right\} .
\end{aligned}
$$

In deriving [A-5], the recurrence formula and the Wronskian of the Bessel functions, together with $[\mathrm{A}-2]$, have been used. Consequently, the current distribution may now be expressed as

$$
\begin{array}{rlrl}
I_{t n}(z)= & \left(\frac{i 4 k_{o} E_{o n}}{\zeta_{0} k_{n}}\right) \int_{-\infty}^{\infty}\left[\left(k_{o}^{2}-k_{n}^{2}\right)-\lambda^{2}\right]^{-1}\left\{1-\left[J_{o}\left(k_{n} b\right) H_{o}^{(1)}(\xi a)\right]^{-1}\right. \\
& \left.J_{o}\left(k_{n} a\right) H_{o}^{(1)}(\xi b)\right\} e^{-i \lambda z} d \lambda ; & 0 \leq z \leq \infty .
\end{array}
$$

Notice that there are no poles at $\xi= \pm \mathrm{k}_{\mathrm{n}}$. For $\mathrm{z} \neq 0$, deformation of the integration path from the real axis in the $\lambda$-plane onto the upper branch cut is possible:

$$
\begin{aligned}
I_{t n}(z)= & I_{o n}\left\{\int_{0}^{k}\left[\lambda^{2}+\left(k_{n}^{2}-k_{o}^{2}\right)\right]^{-1} Q\left(\sqrt{k_{o}^{2}-\lambda^{2}}\right) e^{i \lambda z_{d}} d\right. \\
& \left.-i \int_{0}^{\infty}\left[\lambda^{2}-\left(k_{n}^{2}-k_{o}^{2}\right)\right]^{-1} Q\left(\sqrt{k_{o}^{2}+\lambda^{2}}\right) e^{-\lambda z} d \lambda\right\} ;
\end{aligned}
$$

[A - 7]

$0 \leq \mathrm{z} \leq \infty$ 
In $[A-7]$,

$$
I_{\text {on }}=\left(\frac{8 \mathrm{k}_{\mathrm{o}} \mathrm{E}}{\zeta_{\mathrm{o}} \mathrm{k} n}\right)\left[\mathrm{J}_{\mathrm{o}}\left(\mathrm{k}_{\mathrm{n}} \mathrm{b}\right)\right]^{-1} \mathrm{~J}_{\mathrm{o}}\left(\mathrm{k}_{\mathrm{n}} \mathrm{a}\right)
$$

and

$$
Q(x)=\left[J_{0}^{2}(a x)+Y_{0}^{2}(a x)\right]^{-1}\left[Y_{0}(a x) J_{0}(b x)-Y_{0}(b x) J_{0}(a x)\right] .
$$

Equation [A-7] now can be evaluated numerically. The integration from large $\lambda$ to $\infty$ may be carried out analytically by using the asymptotic expression of $\mathrm{Q}(\mathrm{x})$. For small z (i.e., $\mathrm{k}_{\mathrm{o}} \mathrm{z} \sim 1$ ), the contribution to $\mathrm{I}_{\mathrm{t}}(\mathrm{z})$ comes mainly from $\lambda \sim \mathrm{k}_{\mathrm{n}}$ in the second integration. Since the second integrand also decays exponentially for large $\lambda$, it is not difficult to understand why the current distribution resulting from the higher order mode excitation decays faster as it moves away from the excitation gap. On the other hand, for TEM-mode excitation $\left(k_{n}=0\right)$, the contribution to $I_{t}(z)$ comes mainly from $\lambda \sim \mathrm{k}_{\mathrm{O}}$ in the first integration which has an exponential term behaving like $e^{i k_{o} z}$, as $k_{o} z>1$.

Based on $[A-7]$, the normalized current distribution $I_{t}(z) / I_{\text {on }}$ which is driven by the first three $\mathrm{TM}$ on -mode excitations, is plotted against the distance $\mathrm{k}_{\mathrm{o}} \mathrm{z}$ in Figures 6 through 8 for various antenna radii and gap ratios. For example from Figure 6 if $\mathrm{k}_{\mathrm{o}} \mathrm{h}>\pi / 5(\mathrm{~h}>\lambda / 10)$ and $\mathrm{b} / \mathrm{a}=3$, reflection of the current associated with the $\mathrm{TM}_{01}$ to $\mathrm{TM}_{03}$ modes would 
be negligibly small, thus verifying the applicability of [35] in the practical range of coaxial cable characteristic impedances, i.e., $Z_{c} \simeq 50$ ohms. For thicker monopoles, end reflections increase for the same gap ratios (Figures 7 and 8). Even then when $\mathrm{k}_{\mathrm{o}} \mathrm{a}<1$ and $\mathrm{k}_{\mathrm{o}} \mathrm{b}<1$, the use of the feedpoint correction based on infinite antenna theory is justified. But when $k_{0} a \geq 1$, the gap ratio has to be very small (i.e., $\left.[(b-a) / a<<1]\right)$. In this case the feedpoint correction can be obtained analytically (Chang, Wu 1968). 


\section{APPENDIX B}

Define the exponential integral $E_{S}(x)$ as

$[B-1]$

$$
E_{S}(x)=\int_{X}^{\infty} e^{-x t} t^{S} d t ;
$$

where $\mathrm{s}$ is an integer. Then all $\mathrm{E}_{\mathrm{s}}(\mathrm{x})$ for $\mathrm{s}>1$ can be expressed in terms of $E_{1}(x)$ which is a tabulated function. Thus, if the large argument expansion is made for the integrand in [26], then

$$
\begin{aligned}
C_{1}\left(\lambda, X_{L}, X_{K}\right)= & \frac{i 2}{\pi} \int_{\lambda}^{\infty} d \lambda\left[\sqrt{\left.1+\lambda^{2} K_{o}(\lambda A)\right]^{-1} K_{1}\left(\lambda X_{K}\right)}\right. \\
& {\left[K _ { o } \left(\lambda A_{0} I_{o}\left(\lambda X_{L}\right)-I_{o}\left(\lambda A_{0} K_{o}\left(\lambda X_{L}\right)\right]\right.\right.} \\
\cong & \left(4 X_{L} X_{K}\right)^{-1 / 2}\left[R_{+} E_{2}\left(\lambda R_{+}\right)-R_{-} E_{2}\left(\lambda R_{-}\right)\right. \\
& +\left(\frac{3}{8 X_{K}}+\frac{1}{4 A}-\frac{1}{8 X_{L}}+\frac{R_{+}}{2}\right) R_{+}^{2} E_{3}\left(\lambda R_{+}\right) \\
& \left.-\left(\frac{3}{8 X_{K}}+\frac{1}{8 X_{L}}+\frac{R_{-}}{2}\right) R_{-}^{2} E_{3}\left(\lambda R_{-}\right)\right]
\end{aligned}
$$


where $R_{+}=\left(X_{L}+X_{K}-2 A\right) \lambda$ and $R_{-}=\left|X_{L}-X_{K}\right|$. In the above expression, notice that $\lambda R_{-} \sim 1$ even if $\lambda_{3} A \gg 1$. Similarly

$$
\begin{aligned}
& C_{2}\left(\lambda, X_{L}, X_{K}\right) \cong\left(4 X_{L} X_{K}\right)^{-1 / 2}\left[R_{+} E_{2}\left(\lambda R_{+}\right)+R_{-} E_{2}\left(\lambda R_{-}\right)\right. \\
&+\left(\frac{3}{8 X_{K}}+\frac{1}{4 A}-\frac{1}{8 X_{L}}+\frac{R_{+}}{2}\right) R_{+}^{2} E_{3}\left(\lambda R_{+}\right) \\
&\left.+\left(\frac{R}{2}-\frac{1}{8 X_{L}}-\frac{3}{8 X_{K}}\right) R_{-}^{2} E_{3}\left(\lambda R_{-}\right)\right] ; \\
& {[B-3] \quad C_{3}(\lambda, B, A) \cong\left(\frac{A}{B}\right)^{1 / 2}\left[E_{2}\left(\lambda R_{-}\right)-\frac{1}{8}\left(\frac{1}{A}-\frac{1}{B}\right) E_{3}\left(\lambda R_{-}\right)\right]-\frac{1}{\lambda} . }
\end{aligned}
$$




\section{LIST OF REFERENCES}

CHANG, D. C., 1967, Radio Science, NBS, Vol. 2, No. 9, 1043.

CHANG, D. C., 1968, IEEE Trans. on Ant. and Prop., Vol. AP-16 No. 1, 58.

CHANG, D. C., 1968, IEEE Trans. on Ant. and Prop., Vol. AP-16, No. 5,606 .

CHANG, D. C. and WU, T. T., 1968, Radio Science, Vol. 3 (new series), No. 6, 639 .

HARRINGTON, R. F., 1967, Proc. IEEE, Vol. 55, 136. TAYLOR, C. D. and ARONSON, E. A., 1967, IEEE Trans. on Ant. and Prop., Vol. AP-15, Na. 5, 695. WU, T. T., 1962, J. of Math. Phys., Vol. 3, No. 6, 1298. 
DUNCAN, R. H. and HINCHEY, F. A., 1960, J. Res, NBS (Radio Prop.), No. 5, 569 . EINARSSON, O., 1966, IEEE Trans. on Ant. and Prop., Vol. AP-14, No. $1,31$.

KING, R. W. P., 1956, Theory of Linear Antennas.

KING, R. W. P., ARONSON, E. A., and HARRISON, C. W., JR., 1966, Radio Science, Vol. 1, (new series), 835.

MEI, K. K., 1965, IEEE Trans. on Ant. and Prop., Vol. AP-13, No. 3, 374.

OTTO, D. V., 1967, Radio Science, NBS, Vol. 2, No. 9, 1031. 


\section{LEGEND FOR FIGURES}

Figure 1. Geometry of the Radiating System

Figure 2. Complex $\lambda$ Plane

Figure 3. Standard Admittance $Y$ of a Tubular Monopole Against Normalized Length $h / \lambda$ for Selected Values of $b / a$ and $a / \lambda$. The TEM plus 400 higher order modes are included in these results.

Figure 4. Standard Admittance $\mathrm{Y}$ of a Tubular Monopole Against Normalized Length $h / \lambda$ for Selected Values of $b / a$ and $a / \lambda$. The TEM plus 400 higher order modes are included in these results.

Figure 5. Standard Admittance $\mathrm{Y}$ of a Tubular Monopole Against Normalized Length $h / \lambda$ for Selected Values of $b / a$ and $a / \lambda$. The TEM plus 400 higher order modes are included in these results.

Figure 6. Normalized Current Distribution Versus Distance for $\mathrm{k}_{\mathrm{o}} \mathrm{a}=0.03$

Figure 7. Normalized Current Distribution Versus Distance for $\mathrm{k}_{\mathrm{o}} \mathrm{a}=0.10$ Figure 8. Normalized Current Distribution Versus Distance for $\mathrm{k}_{\mathrm{o}} \mathrm{a}=0.30$ 


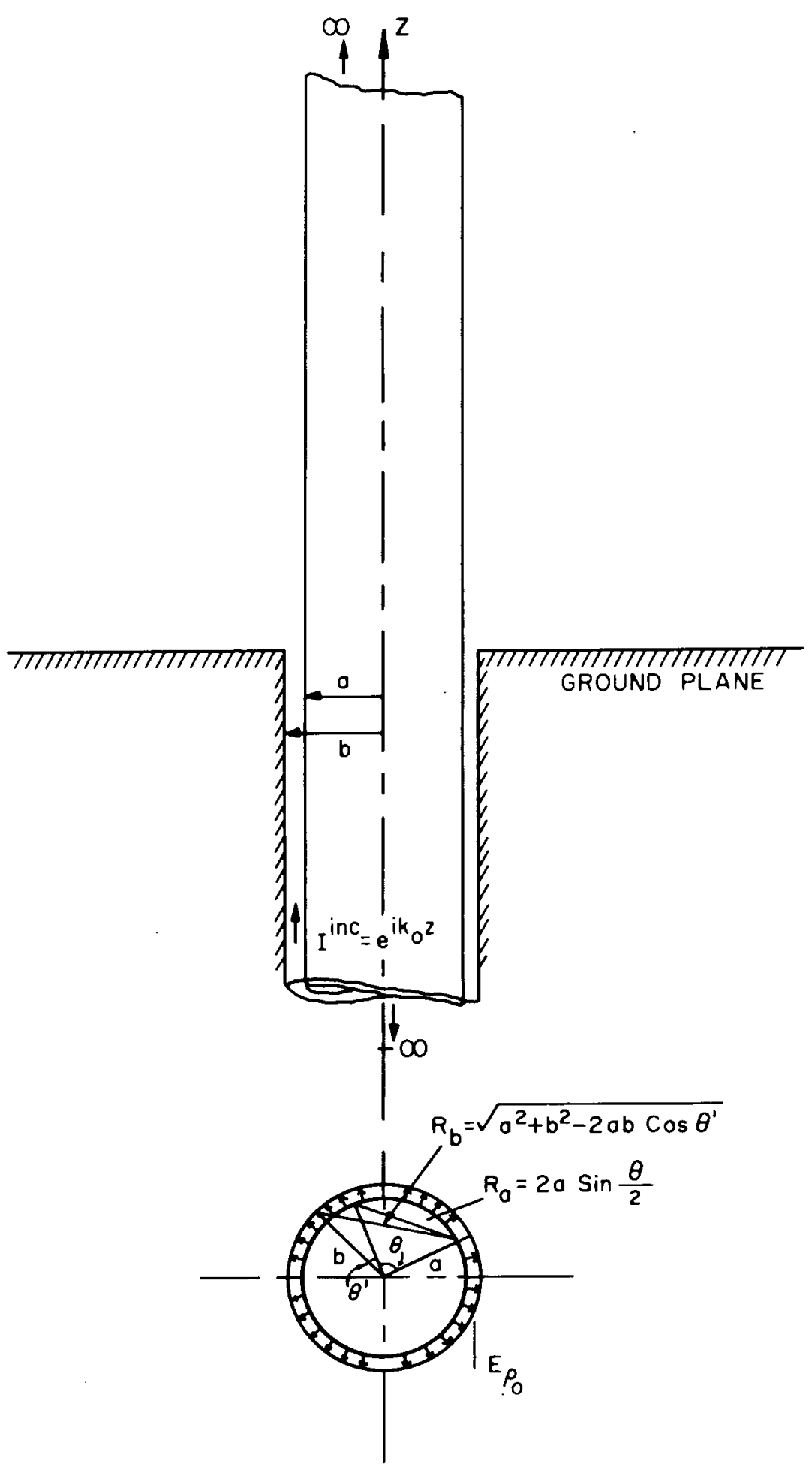

Chang and Harrison - Figure 1

Precise Admittance of a Monopole 


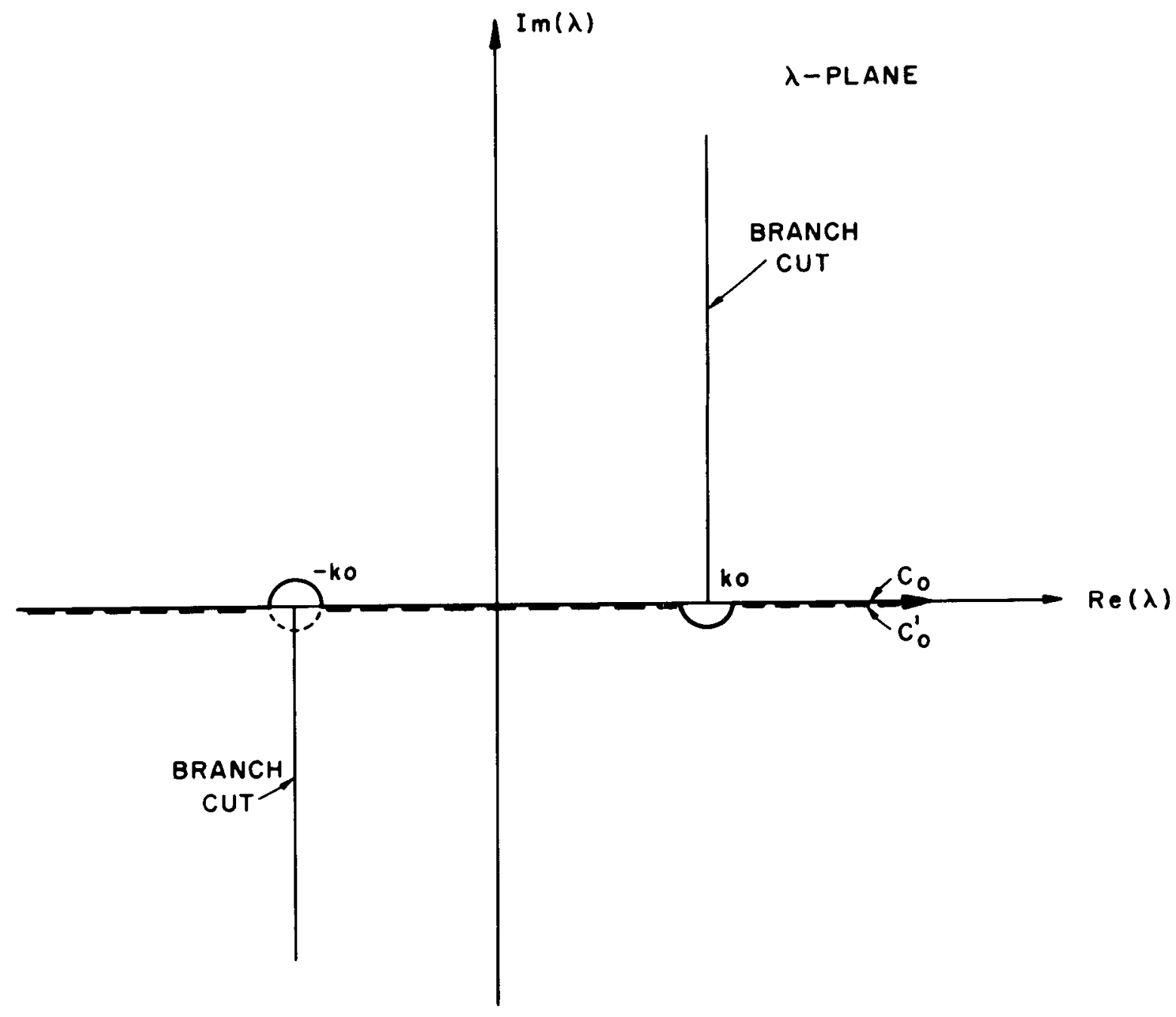

Chang and Harrison - Figure 2

Precise Admittance of a Monopole

39 


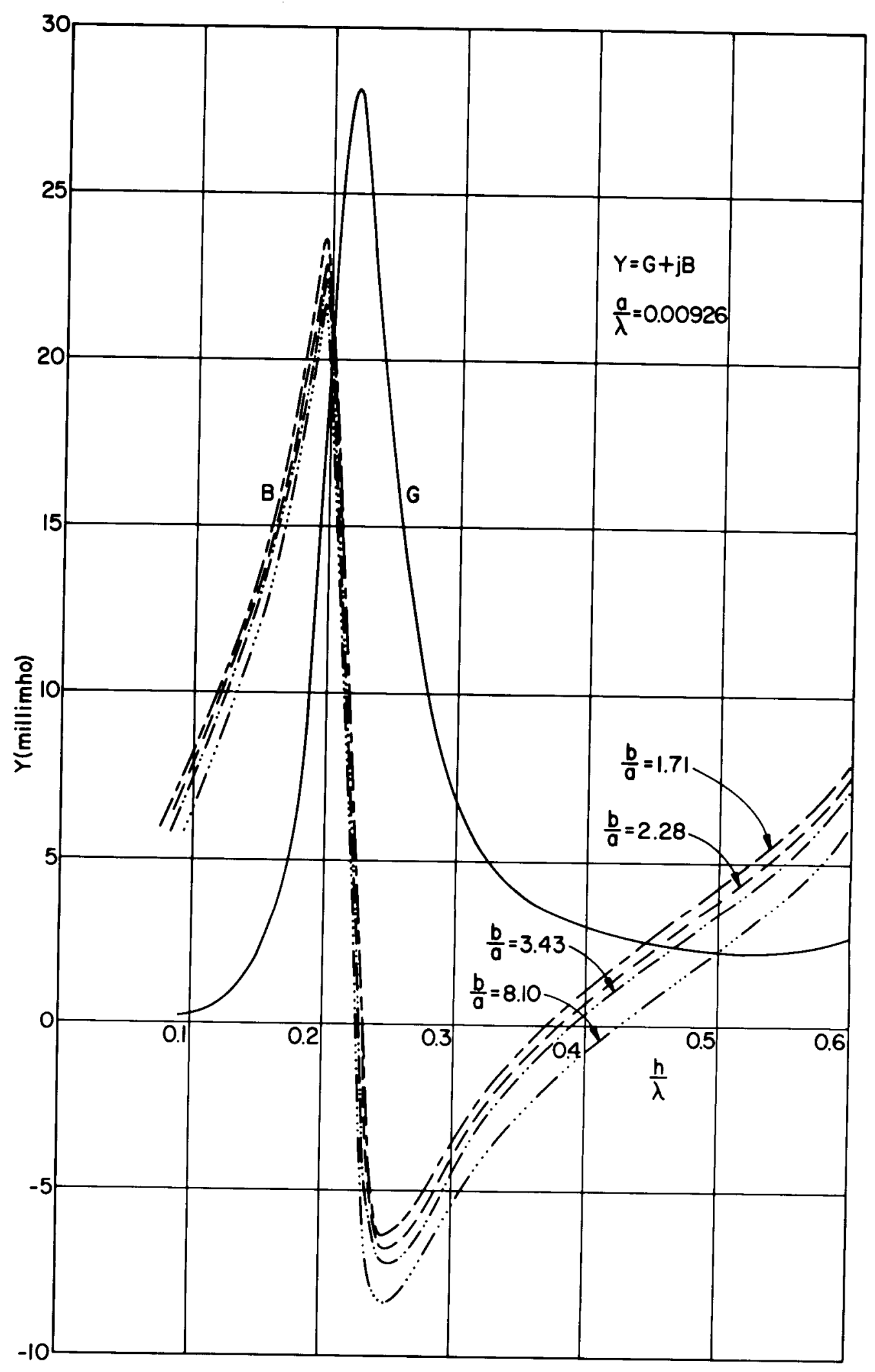




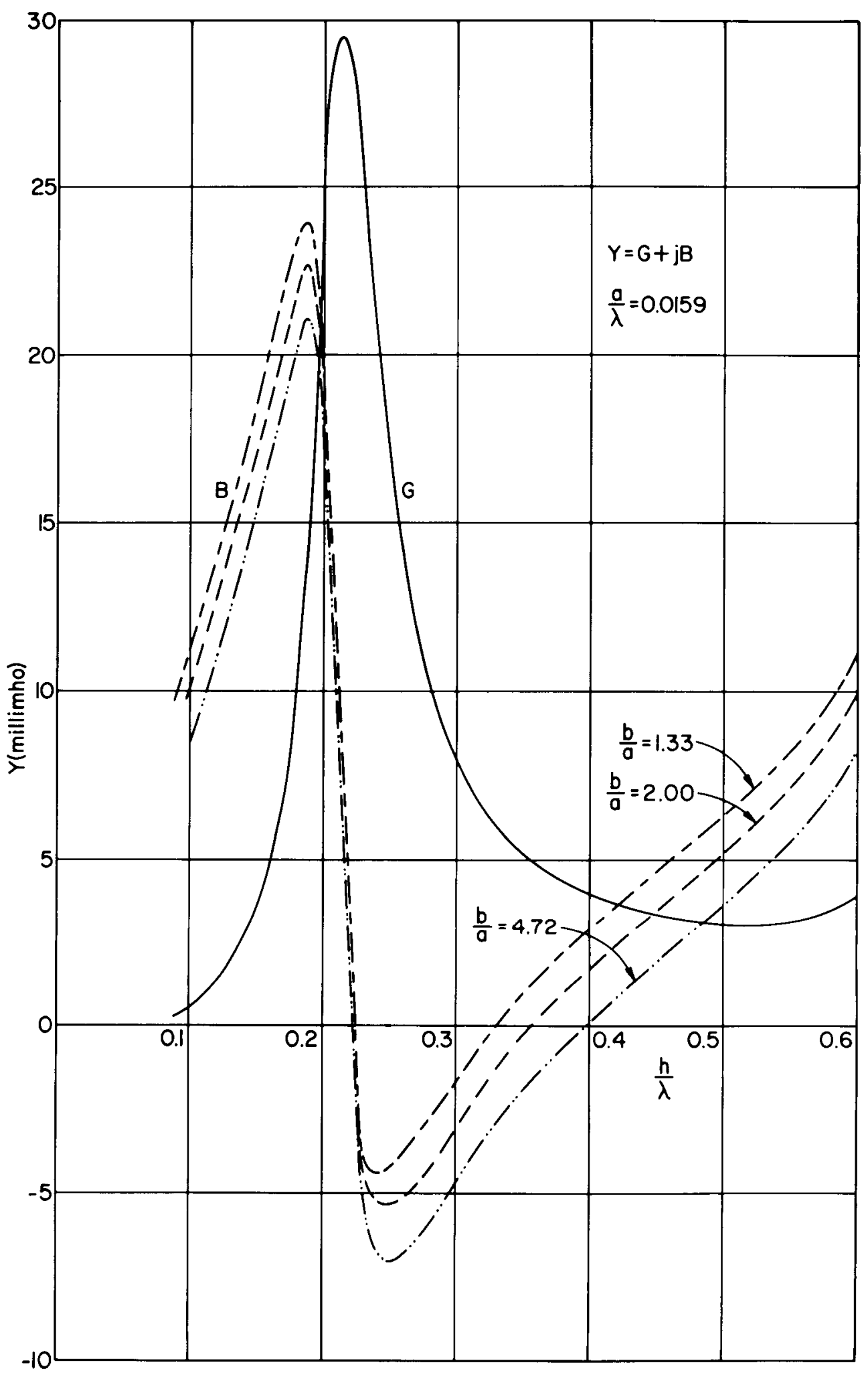




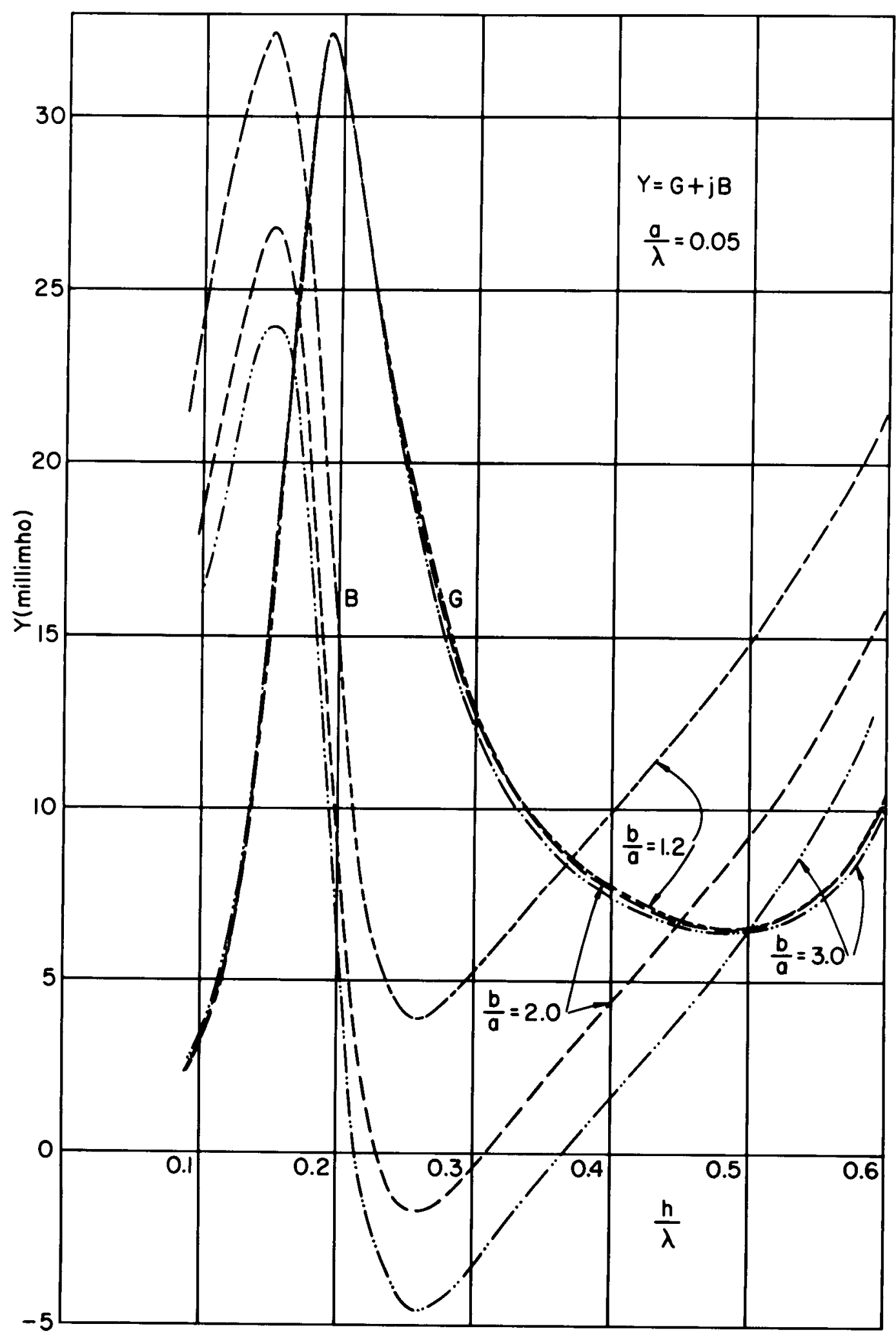




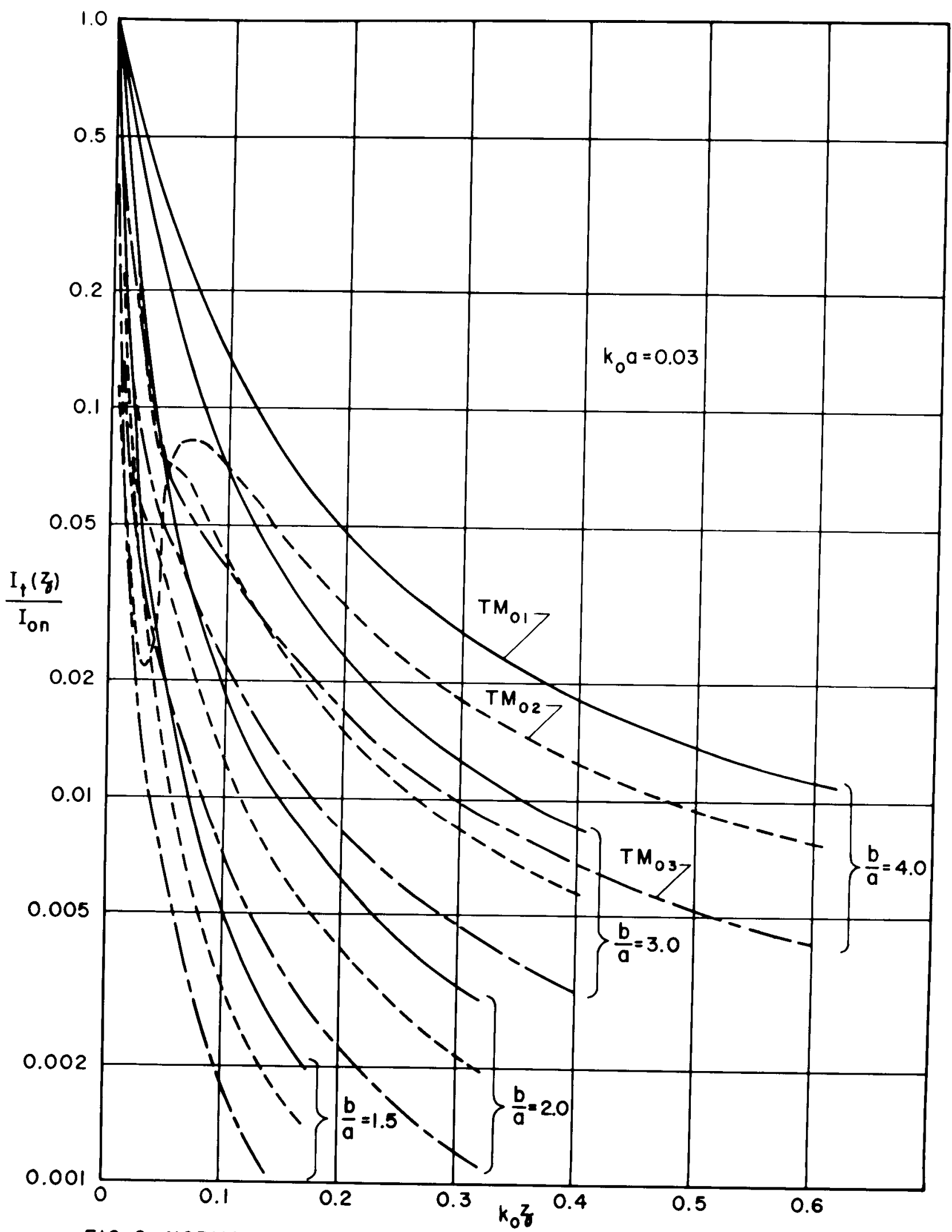

FIG. 6 NORMALIZED CURRENT DISTRIBUTION VS. DISTANCE FOR $k_{0} a=0.03$ 


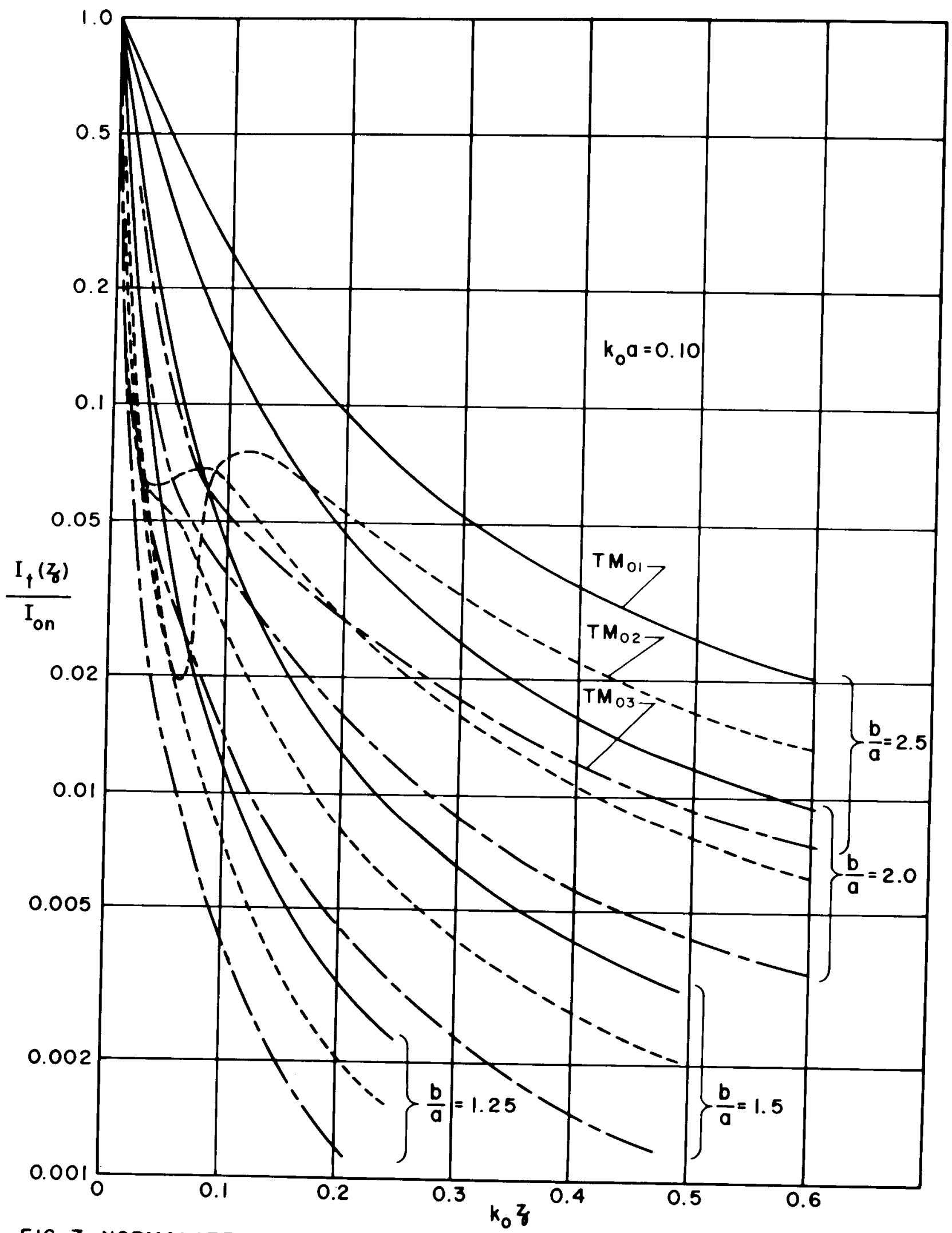

FIG. 7 NORMALIZED CURRENT DISTRIBUTION VS. DISTANCE FOR $k_{0} a=0.10$ 


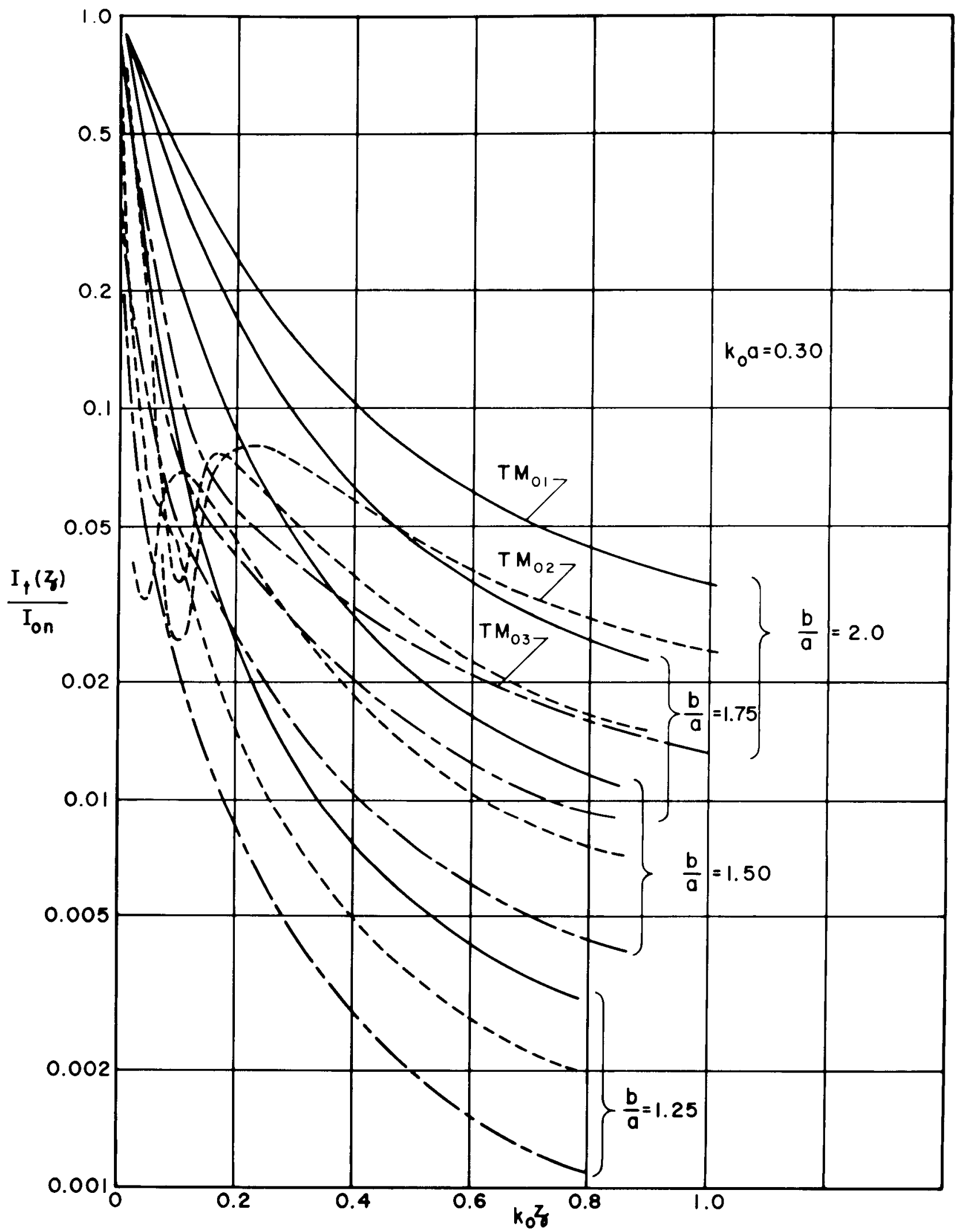

FIG. 8 NORMALIZED CURRENT DISTRIBUTION VS. DISTANCE FOR $k_{0} a=0.30$ 